\title{
Changes in Rates and Content of Primary Care Visits Within an Evolving Health Care System
}

\author{
Donald E. Patbman, MD, MPH \\ University of North Carolina at Chapel Hill, Chapel Hill, North Carolina \\ Ann Fam Med 2019;17:482-484. https://doi.org/10.1370/afm.2477.
}

I $\mathrm{t}$ is no secret to patients and clinicians that the past decade has brought many changes to the organization, operations, and financing of health care in the United States. The Patient Protection and Affordable Care Act of 2010 (ACA) expanded the number of insured and otherwise reduced costs as a barrier to care, bolstered federal safety net programs, and promoted coverage of preventive services and wellness programs. ${ }^{1-4}$ The advent of the patient-centered medical home and primary care practice redesign has broadened services provided both during and between office visits through care teams that can include health coaches, panel managers, patient navigators, and care coordinators. ${ }^{5,6}$ Electronic medical records (EMRs) have become central to patient care, supporting chronic disease and preventive care management, promoting quality of care for set metrics, and providing new ways for patients, staff, and physicians to communicate. Institutional reorganization and new financing models now have most physicians working in practices that have contracted with accountable care organizations (ACOs) and other value-based payment arrangements, becoming responsible for the health and care of a growing $10 \%$ of the US population. ${ }^{7}$ Care previously received from standalone outpatient practices and siloed hospitals is now often received through regional integrated health care systems, with their centralized management, standardized protocols, and growing incentives for patients and clinicians. For the first time, fewer than one-half of physicians work in practices they own. ${ }^{7}$

Conflicts of interest: author reports none.

\section{CORRESPONDING AUTHOR}

Donald E. Pathman, MD, MPH

Department of Family Medicine

University of North Carolina at Chapel Hill

William B. Aycock Building

UNC-CH CB \#7595

Chapel Hill, NC 27599

don_pathman@unc.edu
These many changes were designed for generally laudable goals: to promote access to care, reduce costs of care, enhance quality of care, emphasize primary care and prevention, shape services around the needs of patients, and create a better patient experience. It is appropriate to now ask if the goals of these many changes are being reached. With so many changes occurring simultaneously, are these health care system's changes working as intended, particularly in primary care? Surely, some changes will have largely reached their goals, but other changes will have had only a small impact and not be worth their costs. And the positive effects of still other changes must be weighed against their unanticipated negative effects. For example, despite EMRs' many benefits to patient care, they have also led to "note bloat," added substantial documentation work for clinicians, contributed to physician burnout, and altered key dynamics in the patientphysician encounter. ${ }^{8-12}$ Making fundamental changes to the delivery of complex and costly services within a complex industry can also create perverse incentives for patients, clinicians, provider organizations, and insurers to respond in unintended ways that can undermine goals. In one example from the early 1990s, Congress substantially reduced the amounts Medicare paid for many overpriced surgical procedures to reduce federal health care costs. Surgeons responded-likely both intentionally and unintentionally-by increasing the number of these procedures they performed for patients with Medicare and also for those with private insurance, so in the end, cost savings for the government and US health care overall were blunted. ${ }^{13,14}$

In this issue of Annals of Family Medicine, papers by Rao et $\mathrm{al}^{15}$ and Johansen and Richardson ${ }^{16}$ document how primary care office visits have changed for patients during the past 10 -year period with its many changes in health care. These papers have different foci: Rao et $\mathrm{al}^{15}$ on primary care practice resources and visit rates and Johansen and Richardson ${ }^{16}$ on updating the "ecology of medical care model."17,18 But together their studies provide complementary trend data to 
shed light on why the average number of visits per person to primary care physicians is decreasing..$^{19,20}$ This downward trend in a key primary care service metric is unexpected at a time when financial barriers to care have decreased and preventive and wellness care are promoted. This editorial triangulates findings of the many tracked outcomes of these 2 studies, which together provide a fuller picture of the ways that use of services is changing. Taking this wider look is key to detecting unintended effects from changes in a system often likened to a balloon that, when squeezed from some sides, responds by bulging in other directions.

The first paper, "National Trends in Primary Care Visit Use and Practice Capabilities, 2008-2015" by Rao et al ${ }_{1}^{15}$ draws on annual National Ambulatory Medical Care Survey (NAMCS) medical record abstraction data collected from a nationally representative sample of adults' office visits to primary care physicians. ${ }^{21}$ Over the 10-year study period from 2007 to 2016, primary care practices became more likely to use EMRs and to offer secure messaging, e-mail consults, and afterhour visits to patients. Data also confirmed that annual mean number of visits per person to primary care physicians decreased-by $20 \%$ in these data-and fell specifically for acute and chronic disease care needs but not for general medical exams and mental health visits. Decreases in annual primary care visit numbers were reported for all patient subgroups assessed: all 4 race-ethnicity groups, all 4 health insurance coverage groups, and in both metropolitan and rural areas. But while primary care visit numbers per individual decreased overall, the duration of primary care office visits increased by 2.4 minutes on average, and each visit addressed more diagnoses and medications and provided more preventive services and procedures.

The second paper, "The Ecology of Medical Care Before and After the Affordable Care Act: Trends From 2002-2016" by Johansen and Richardson, ${ }^{16}$ documents changes in use rates in a variety of types of patient services. This study uses Medical Expenditure Panel Survey (MEPS) data from repeated interviews of rolling study cohorts representative of non-institutionalized adults nationally. ${ }^{22}$ Focusing on the most relevant findings over the 2002 to 2016 study period, the likelihood of visiting a primary care physician at least once in a month (presented by the authors as number of individuals out of 1,000 that visited a primary care physician in each calendar month, averaged for each calendar year) fell for adults as a whole and for all age subgroups. The likelihood of being hospitalized similarly fell for adults overall and all age groups. The likelihood of visiting a specialist physician also decreased for adults aged younger than 65 years but increased for those aged 65 years and older. And the likelihood of an emergency department visit did not change for those aged 18 to 40 years and those aged 65 years and older, but increased for those aged 41 to 65 years.

The findings of these 2 studies taken together more convincingly suggest than either alone why the average number of yearly visits to primary care physicians is decreasing. As Rao et al point out ${ }_{1}^{15}$ it might be that patients and physicians feel the need for fewer office visits now that visits are more comprehensive and between-visit capacity for outreach to patients is greater and communications are easier. One can intuit the contributions of a broadening health care team in these data that show more services provided during office visits that are only modestly longer in duration and patients having more communication avenues. However, data on team composition and use were not available to their study to test this point. Data provided by Johansen and Richardson ${ }^{16}$ help lay to rest the health-care-system-as-a-balloon concern that as visits to primary care physician offices have decreased, visits to other providers and settings have increased. In their study, visits to specialists and hospitalizations did not increase, and only for adults aged 41 to 65 years did emergency visits increase. Taken together, the findings of these 2 studies suggest that the falling rate of primary care physician visits for adults aged younger than 65 years is best explained by changes in the content and processes surrounding the primary care visit, and generally not due to care shifting to specialist physicians, emergency departments, and hospitals. This is welcome outcome data for primary care practice redesign.

These studies nicely fill in important pieces in the health care service use trend puzzle. They also raise other questions. One wonders if the rapid growth in high-deductible health plans also contributes to falling primary care visit numbers. ${ }^{23}$ Future studies should also assess how changes in the content and number of primary care visits correlates with trends in quality of care, costs, people's health, and patients' satisfacton with care, as well as clinicians' work stress and burnout.

To read or post commentaries in response to this article, see it online at http://www. AnnFamMed.org/content/17/6/482.

Submitted October 1, 2019; accepted October 1, 2019.

Key words: primary care visits; Medical Expenditure Panel Survey; MEPS; NAMCS; National Ambulatory Medical Care Survey; health policy; program evaluation; Patient Protection and Affordable Care Act

\section{References}

1. Kaiser Family Foundation. Health Reform. Summary of the Affordable Care Act. https://www.kff.org/health-reform/fact-sheet/ summary-of-the-affordable-care-act/. Published Apr 25, 2013. Accessed Oct 6, 2019. 
2. Collins SR, Bhupal HK, Doty MM. Health insurance coverage eight years after the ACA. Commonwealth Fund Report. https://www. commonwealthfund.org/publications/issue-briefs/2019/feb/healthinsurance-coverage-eight-years-after-aca. Published Feb 7, 2019. Accessed Oct 2, 2019.

3. Pathman DE, Konrad TR. Growth and changes in the NHSC workforce with the American Recovery and Reinvestment Act. J Am Board Fam Med. 2012;25(5):723-733.

4. Paradise J, Rosenbaum S, Markus A, et al. Findings Brief. Community health centers: recent growth and the role of the ACA. Kaiser Family Foundation. https://www.kff.org/report-section/communityhealth-centers-recent-growth-and-the-role-of-the-aca-issue-brief/. Published Jan 18, 2017. Accessed Oct 7, 2019.

5. Schottenfeld L, Petersen $D$, Peikes $D$, et al. White paper: creating patient-centered team-based primary care. AHRQ Pub. No. 16-0002-EF. https://pcmh.ahrq.gov/page/creating-patient-centeredteam-based-primary-care. Published Mar 2016. Accessed Oct 2, 2019.

6. Fraher E, Machta R, Halladay J. The workforce transformations needed to staff value-based models of care. Research Brief, North Carolina Health Workforce Research Center. https://www. shepscenter.unc.edu/wp-content/uploads/2015/12/DataBrief_ ValueBasedWorkforce_FraherMachtaHalladay_final.pdf. Published Nov 2015. Accessed Oct 2, 2019.

7. Rama A. Payment and delivery in 2018: participation in medical homes and accountable care organizations on the rise while feefor-service revenue remains stable. https://www.ama-assn.org/ system/files/2019-09/prp-care-delivery-payment-models-2018.pdf. American Medical Association. Published Aug 2019. Accessed Oct 1, 2019.

8. Gardner RL, Cooper E, Haskell J, et al. Physician stress and burnout: the impact of health information technology. J Am Med Inform Assoc. 2019;26(2):106-114.

9. Shanafelt TD, Dyrbye LN, Sinsky C, et al. Relationship between clerical burden and characteristics of the electronic environment with physician burnout and professional satisfaction. Mayo Clin Proc. 2016;91(7):836-848.

10. Arndt BG, Beasley JW, Watkinson MD, Tuan W-J, Sinsky CA, Gilchrist VJ. Tethered to the EHR: primary care physician workload assessment using EHR event log data and time-motion observations. Ann Fam Med. 2017;15(5):419-426.

11. Kuhn T, Basch P, Barr M, Yackel T; Medical Informatics Committee of the American College of Physicians. Clinical documentation in the 21st century: executive summary of a policy position paper from the American College of Physicians. Ann Intern Med. 2015;162(4): 301-303.
12. Ventres W, Kooienga S, Vuckovic N, Marlin R, Nygren P, Stewart $V$. Physicians, patients, and the electronic health record: an ethnographic analysis. Ann Fam Med. 2006;4(2):124-131.

13. Yip WC. Physician response to Medicare fee reductions: changes in the volume of coronary artery bypass graft (CABG) surgeries in the Medicare and private sectors. J Health Econ. 1998;17(6):675-699.

14. Rice T, Stearns SC, Pathman DE, DesHarnais S, Brasure M, Tai-Seale M. A tale of two bounties: the impact of competing fees on physician behavior. J Health Polit Policy Law. 1999;24(6):1307-1330.

15. Rao A, Shi Z, Ray KN, Mehrotra A, Ganguli I. National trends in primary care visit use and practice capabilities, 2008-2015. Ann Fam Med. 2019;17(6):538-544.

16. Johansen ME, Richardson CR. The ecology of medical care before and after the Affordable Care Act: trends from 2002-2016. Ann Fam Med. 2019;17(6):526-537.

17. White KL, Williams TF, Greenberg BG. The ecology of medical care. N Engl J Med. 1961;265:885-892.

18. Green LA, Fryer GE Jr., Yawn BP, Lanier D, Dovey SM. The ecology of medical care revisited. N Engl J Med. 2001;344(26):2021-2025.

19. Ganguli I, Lee TH, Mehrotra A. Evidence and implications behind a national decline in primary care visits. J Gen Intern Med. 2019. https://link.springer.com/article/10.1007\%2Fs11606-019-05104-5. Accessed Oct 16, 2019.

20. Chou S-C, Venkatesh AK, Trueger NS, Pitts SR. Primary care office visits for acute care dropped sharply in 2002-15, while ED visits increased modestly. Health Aff (Millwood). 2019;38(2):268-275.

21. National Center for Health Statistics, Centers for Disease Control and Prevention. Ambulatory health care data. https://www.cdc. gov/nchs/ahcd/index.htm. Updated Sept 20, 2019. Accessed Oct 3, 2019.

22. Agency for Healthcare Research and Quality. Medical expenditure panel survey. https://meps.ahrq.gov/mepsweb/index.jsp. Accessed Oct 6, 2019.

23. Cohen RA. Zammittee EP. High-deductible Health Plan Enrollment Among Adults Aged 18-64 With Employment-based Insurance Coverage. NCHS Data Brief number 317, August 2018. https://www.cdc. gov/nchs/data/databriefs/db317.pdf. Accessed Oct 15, 2019. 